\title{
STUDY OF SERUM URIC ACID LEVEL IN PATIENTS WITH TYPE 2 DIABETES MELLITUS
}

KEY WORDS:

\section{Rohit Mathew*}

\section{Aswathy Joseph}

Resident $3^{\text {rd }}$ year, Department of General Medicine, Jhalawar Medical College,Jhalawar, Rajasthan, India. *Corresponding Author

Resident $2^{\text {nd }}$ year, Department of General Medicine, Jhalawar Medical College, Jhalawar, Rajasthan,India.

BACKGROUND:Diabetes mellitus is a group of metabolic diseases characterized by hyperglycemia resulting from defects in insulin secretion, insulin action, or both.

AIM:To evaluate the serum uric acid level in patients with type 2 Diabetes mellitus.

MATERIALS AND METHODS:It was a prospective observational study conducted on 100 patients attending Medicine Department of Jhalawar Medical College, Jhalawar, Rajasthan. The study was done to assess the uric acid status in patients with diabetes mellitus and to find out its association with Age, Gender, Body Mass Index (BMI), Waist Hip Ratio (WHR), Dyslipidemia and Hypertension. Relevant history, vitals, clinical examination and laboratory investigations were done and recorded.

RESULTS:This study evaluated the level of serum uric acid in Type 2 diabetes mellitus patients and confirmed there significantly high prevalence of hyperuricemia among type 2 diabetes subjects and increased association with increasing age, BMI,WHR, Dyslipidemia, Hypertension and female sex.

CONCLUSION: Patients with Poor metabolic control and longer duration of diabetes were more susceptible to develop various complications including hyperuricemia. Early diagnosis and control of Diabetes Mellitus and its complications is indicated and potential therapeutic approaches (therapeutic life style changes and pharmacotherapy) should be initiated.

\section{INTRODUCTION}

\section{DIABETES MELLITUS}

Diabetes mellitus is a group of metabolic diseases characterized by hyperglycemia resulting from defects in insulin secretion, insulin action, or both. The chronic hyperglycemia of diabetes is associated with long-term damage, dysfunction, and failure of various organs, especially the eyes, kidneys, nerves, heart, and blood vessels ${ }^{1}$. Diabetes mellitus is associated with two to four-fold increased incidence of coronary artery disease ${ }^{2}$. Over recent years there has been renewed debate about the nature of the association between raised serum uric acid concentration and diabetic complications. Several large studies have identified the value, in populations, of serum uric acid concentration in predicting the risk of cardiovascular events, such as myocardial infarction.

\section{MATERIALS AND IMETHODS}

It was a prospective observational study conducted on 100 patients attending Medicine Department of Jhalawar Medical College, Jhalawar, Rajasthan. The present study was done to assess the uric acid status in patients with diabetes mellitus and to find out its association with age, gender, BMI, WHR, Dyslipidemia and Hypertension. The relevant history including sociodemographic data, clinical data like Body weight, Height, BMI, WHR, blood pressure, Cardiovascular risk factors and Clinical examination were recorded. All patients were subjected to following laboratory investigations: CBC, Fasting and post prandial blood sugar level, RFT, HbAlc, blood urea, serum creatinine, serum uric acid, lipid profile, ECG, urinalysis and CXR. The data were compiled and analysed using the Statistical Package for Social Sciences (IBM SPSS Inc.).

\section{RESULTS}

Out of the 100 subjects in the study, $58 \%$ were males and $42 \%$ were female subjects. The study sample included majority $41 \%$ in the age group of $61-70$ years (Table 1 ). In the study $55 \%$ belonged to the category of 6-10 years of duration of diabetes whereas $18 \%$ subjects had a duration of $>10$ years of the disease and $27 \%$ had duration $<5$ years since the diagnosis. 19 subjects had a BMI which comes in the obese category. While 40 subjects belonged to normal range of BMI for Asian population and 41 were in the overweight category. Among the study subjects, 25 were having Ischemic heart disease and 29 were having hypertension. Dyslipidemia was present in 23 subjects. The mean uric acid level among study subjects was $5.35 \pm 1.19 \mathrm{mg} / \mathrm{dl}$. Of the 100 subjects, $17 \%$ had hyperuricemia.

Table 1: Age wise distribution of study subjects

\begin{tabular}{|c|c|c|}
\hline Age group & No. & \% \\
\hline Up to 50 years & 16 & 16.0 \\
\hline $51-60$ years & 30 & 30.0 \\
\hline $61-70$ years & 41 & 41.0 \\
\hline $71-80$ years & 13 & 13.0 \\
\hline
\end{tabular}

\section{ASSOCIATION OF GENDER WITH HYPERURICEIMIA}

Among the study subjects, 15 female participants had hyperuricemia while 2 male participants had hyperuricemia. Females had a significantly higher incidence of hyperuricemia compared to male subjects and which was statistically significant with a ' $\mathrm{P}$ ' value of $<0.001$

Table 2: Association of gender with hyperuricemia in diabetic subjects

\begin{tabular}{|c|c|c|c|c|}
\hline \multirow{2}{*}{ Gender } & \multicolumn{2}{|c|}{ No (n=83) } & \multicolumn{2}{c|}{ Yes (n=17) } \\
\cline { 2 - 5 } & No. & \% & No. & \% \\
\hline Male & 56 & 96.6 & 2 & 3.4 \\
\hline Female & 27 & 64.3 & 15 & 35.7 \\
\hline
\end{tabular}

Association of gender with hyperuricemia in diabetic subjects

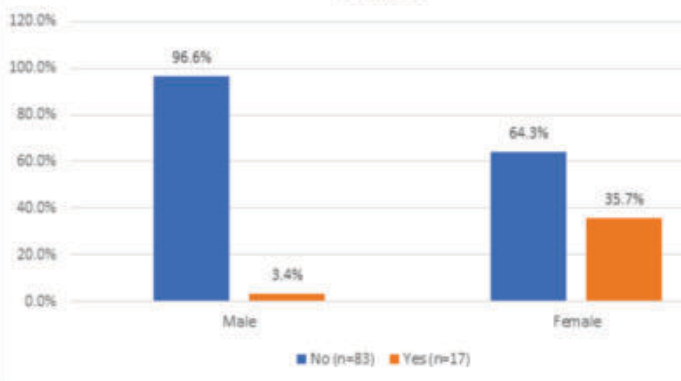

Figure 1: Association of gender with hyperuricemia

ASSOCIATION OF AGE AND ANTHROPOMETRIC PARAMETERSWITH HYPERURICEMIA

Table 3: Association Age with hyperuricemia in diabetic subjects 


\begin{tabular}{|c|c|c|}
\hline & \multicolumn{2}{|c|}{ Hyperuricemia } \\
\hline & No (n=83) & Yes (n=17) \\
\hline Age in years & $60.0 \pm 9.13$ & $70.88 \pm 8.51$ \\
\hline BMI & $24.03 \pm 2.75$ & $25.74 \pm 2.73$ \\
\hline WHR & $0.85 \pm 0.04$ & $0.88 \pm 0.07$ \\
\hline
\end{tabular}

Figure 4: Association of duration of diabetes with hyperuricemia

\section{ASSOCIATION OF HYPERTENSION WITH HYPERURICEMIA IN DIABETIC SUBJECTS}

Figure 2: ASSOCIATION OF AGE WITH HYPER URICEMIA

Association of age with hyperuricemia in diabetic subjects

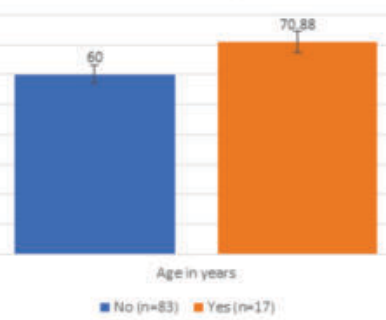

Table 6: Association of hypertension with hyperuricemia in diabetic subjects

\begin{tabular}{|c|c|c|c|c|}
\hline \multirow{2}{*}{ Hypertension } & \multicolumn{2}{|c|}{ No (n=83) } & \multicolumn{2}{c|}{ Yes (n=17) } \\
\cline { 2 - 5 } & No. & $\%$ & No. & $\%$ \\
\hline No & 61 & 85.9 & 10 & 14.1 \\
\hline Yes & 22 & 75.9 & 7 & 24.1 \\
\hline
\end{tabular}

Association of hypertension with hyperuricemia in diabetic subjects
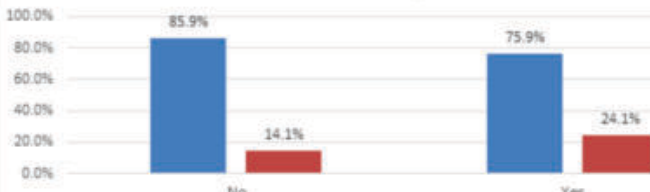

\section{ASSOCIATION OF BIMIWITH HYPERURICEMIA}

Table 4: Association of BMI with hyperuricemia in diabetic subjects

\begin{tabular}{|c|c|c|c|c|}
\hline \multirow{2}{*}{ BMI category } & \multicolumn{2}{|c|}{ No (n=83) } & \multicolumn{2}{c|}{ Yes (n=17) } \\
\cline { 2 - 5 } & No. & \% & No. & \% \\
\hline $18.5-22.99 \mathrm{~kg} / \mathrm{m}^{2}$ & 37 & 92.5 & 3 & 7.5 \\
\hline $23-27.5 \mathrm{~kg} / \mathrm{m}^{2}$ & 33 & 80.5 & 8 & 19.5 \\
\hline$>27.5 \mathrm{~kg} / \mathrm{m}^{2}$ & 13 & 68.4 & 6 & 31.6 \\
\hline
\end{tabular}

Association of BMI with hyperuricemia in diabetic subjects

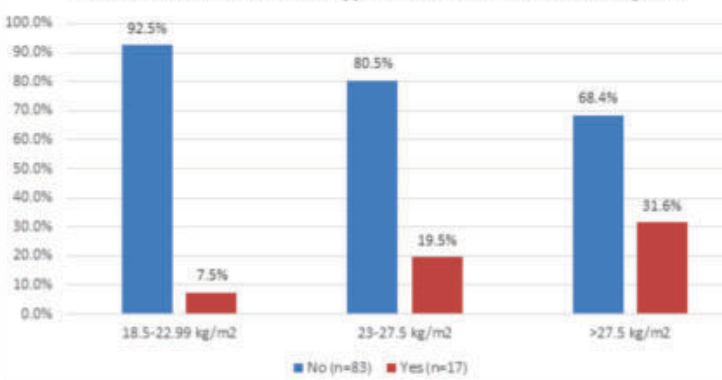

Figure 3: ASSOCIATION OF BMI WITH HYPER URICEIMIA

\section{ASSOCIATION OF DURATION OF DIABETES WITH HYPERURICEMIA}

Table 5: Association of duration of diabetes with hyper uricemia in diabetic subjects

\begin{tabular}{|c|c|c|c|c|}
\hline \multirow{2}{*}{ Duration of diabetes } & \multicolumn{2}{|c|}{ No (n=83) } & \multicolumn{2}{c|}{ Yes (n=17) } \\
\cline { 2 - 5 } & No. & \% & No. & \% \\
\hline 1-5 years & 26 & 96.3 & 1 & 3.7 \\
\hline 6-10 years & 50 & 90.9 & 5 & 9.1 \\
\hline >10 years & 7 & 38.9 & 11 & 61.1 \\
\hline
\end{tabular}

Association of duration of diabetes with hyperuricemia in diabetic subjects

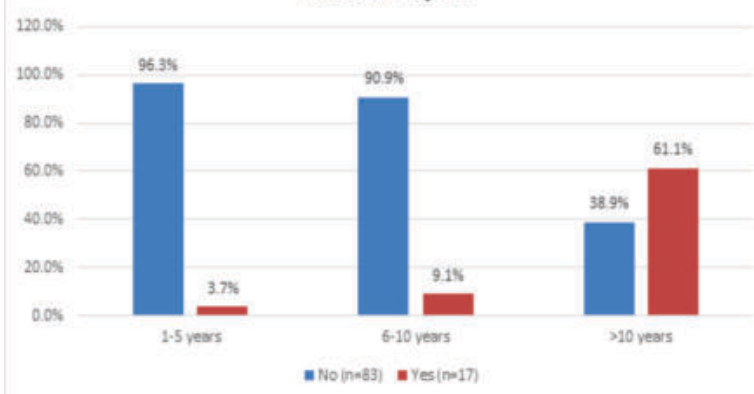

|www.worldwidejournals.com

Figure 5: Association of hypertension with hyper uricemia in diabetic subjects

\section{ASSOCIATION OF DYSLIPIDEMIA WITH HYPER URICEMIA IN DIABETIC SUBJECTS.}

Table 7: Association of dyslipidemia with hyperuricemia in diabetic subjects

\begin{tabular}{|c|c|c|c|c|}
\hline \multirow{2}{*}{ Dyslipidemia } & \multicolumn{2}{|c|}{ No (n=83) } & \multicolumn{2}{c|}{ Yes (n=17) } \\
\cline { 2 - 5 } & No. & \% & No. & \% \\
\hline No & 70 & 90.9 & 7 & 9.1 \\
\hline Yes & 13 & 56.5 & 10 & 43.5 \\
\hline
\end{tabular}

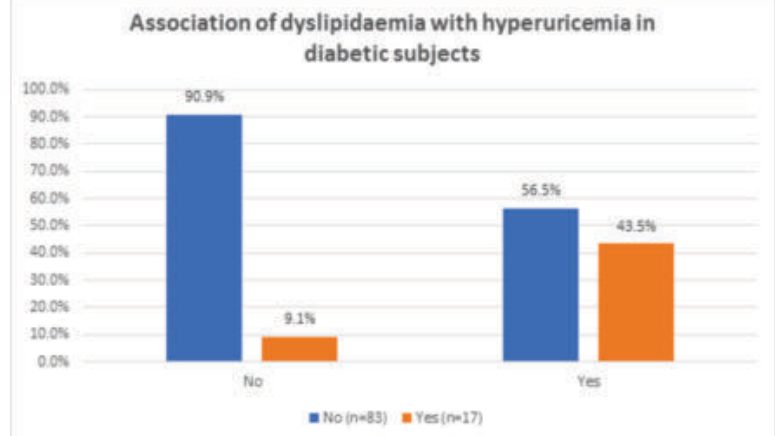

Figure 6: Association of dyslipidemia with hyper uricemia in diabetic subjects

CORRELATION OF HYPERURICEMIA WITH DIFFERENT PARAMETERS.

Table 8: Correlation of serum uric acid with different parameters

\begin{tabular}{|c|c|c|}
\hline & r value & p value \\
\hline Age in years & 0.41 & $<0.001$ \\
\hline Fasting blood sugar & 0.14 & 0.15 \\
\hline PPBS & 0.26 & 0.01 \\
\hline BMI & 0.43 & $<0.001$ \\
\hline WHR & 0.41 & $<0.001$ \\
\hline
\end{tabular}

The Fasting blood sugar had no significant correlation with hyperuricemia while the Post prandial blood sugar has a significant correlation with 'P' value of 0.01

\section{DISCUSSION}

This study evaluated the level of serum uric acid in Type 2 diabetes mellitus patients and confirmed the following:

- Significantly high prevalence of hyperuricemia among type 2 diabetes subjects. Mean uric acid level among 
diabetic patients was $5.35 \pm 1.19 \mathrm{mg} / \mathrm{dl}$. Prevalence of hyperuricemia in general Indian population is still underinvestigated. A study by Bandana Sachdev among select nomadic Rajasthani population reported a prevalence of hyperuricemia as found $13.5 \%{ }^{3}$.

- Serum Uric Acid (SUA) in males was 5.18+/-1.24 while in females it was 5.58+/-1.09. The gender difference in uric acid level was found to be not statistically significant. J Wang et al had reported among Chinese T2DM patients with central obesity the prevalence of hyperuricemia as $36.1 \%$ and in men as $28.4 \%$.

- Significant correlation between increasing age and hyperuricemia in T2DM patients. Billa $G$ et al in their Retrospective study in Indian subjects also reported this trend $^{5}$.

- SUA was also observed to be in the higher level with prolonged duration of illness and was found to be statistically significant with a ' $P$ ' value of $<0.001$. In contrast, Shabana $S$ et al reported a negative relationship with increased duration of illness with $\mathrm{SUA}^{6}$.

- Significant correlation between BMI and higher serum uric acid with a 'P' value of $<0.001$. Ali $\mathrm{N}$ et al also reported significant positive relationship between SUA and obesity among Bangladeshi adults in a cross-sectional study in $2017^{7}$.

- Rathmann et al, assessed the various components of insulin resistance syndrome in young black and white adults. They concluded that body mass index showed strongest positive correlation with the uric acid among insulin resistant components ${ }^{8}$.

- Patient with higher WHR had higher uric acid level when compared with low WHR and it is statistically significant with a 'P' value of $<0.001$.

- In this study the mean SUA in in subjects with hypertension was $6.01+/-1.17$ while non hypertensive subjects had a mean SUA of $5.08+/-1.10$. The difference was statistically significant with a ' $P$ ' value of 0.001 . Strong epidemiologic data have linked serum uric acid to hypertension in humans and experimental animal data suggests hyperuricemia causes -hypertension. ${ }^{9,10}$. The Olivetti heart study had shown an independent positive association between serum uric acid and development of hypertension. ${ }^{11}$

- Mean SUA among subjects with dyslipidemia was $6.26+/-$ 0.91 while in non dyslipidemic subjects were $5.08+/-1.14$ which was found statistically significant with a 'P' value of $<0.001$. Dyslipidemia accelerates atherosclerosis in diabetic subjects. The pathophysiological link between the elevated SUA and atherosclerosis are endothelial dysfunction and inflammation. Reactive Oxygen Species production by Xanthine Oxidase can induce endothelial dysfunction by reducing bioavailability of nitric oxide. ${ }^{12}$

\section{CONCLUSION}

- In our study prevalence of hyperuricemia was found to be $17 \%$ in diabetic population.

- Serum uric acid levels in female subjects was observed higher than males.

- Significantly higher uric acid level was found in subjects with long duration of diabetes and older subjects.

- Significant correlation was noticed between serum uric acid and BMI as well as WHR.

- Elevated uric acid levels were noticed among hypertensive and dyslipidemic subjects.

- Whether uric acid contributes independently to T2DM and coronary artery disease is still a matter of controversy. Multiple studies have shown link between metabolic syndrome and hyperuricemia and which can lead to T2DM and atherosclerotic vascular disease in long term. Patients with Poor metabolic control and longer duration of diabetes were more susceptible to develop various complication including hyperuricemia. Our study also indicates a possible link between higher uric acid levels and diabetes mellitus and metabolic syndrome.

\section{REFERENCES}

1. Ahmed AM. History of diabetes mellitus. Saudi Med J. 2002 Apr;23(4):373-8. PMID: 11953758.

2. Eknoyan G. A history of diabetes mellitus -- a disease of the kidneys that became a kidney disease.JNephrol.2006 May-Jun;19 Suppl 10:S7 1-4.

3. Bandana Sachdev. Prevalence of Hyperuricemia and Its Relation with Metabolic Syndrome in A Select Nomad Tribal Populations of Rajasthan, India; International Journal of Health Sciences \& Research 25 Vol.2; Issue: 4; July 2012.

4. Jiao Wang PhDl, Rong-Ping Chen MDl, Lei Lei PhDl, Qing-Qing Song MDl Prevalence and determinants of hyperuricemia in type 2 diabetes mellitus patients with central obesity in Guangdong Province in China; Asia Pac J Clin Nutr 2013;22(4):590-598.

5. Billa G, Dargad R, Mehta A. Prevalence of Hyperuricemia in Indian Subjects attending Hyperuricemia Screening Programs-A Retrospective Study. The Journal of the Association of Physicians of India. 2018 Apr;66(4):43-46.

6. Shabana S, Sireesha M, Satyanarayana U.(2012).Uric Acid in Relation to Type 2 Diabetes Mellitus Associated with Hypertension, 6(7), 1140-1 143.

7. Ali N, Perveen R, Rahman S, et al. Prevalence of hyperuricemia and the relationship between serum uric acid and obesity: A study on Bangladeshi adults. PLoS One.2018;13(11):e0206850. Published 2018 Nov 1.

8. Rathmann,W., Funkhouser, E., Dyer, A. R., \& Roseman, J. M. (1998). Relations of hyperuricemia with the various components of the insulin resistance syndrome in young black and white adults: the CARDIA study. Coronary Artery Risk Development in Young Adults. Annals of epidemiology, 8(4), 250-261.

9. Mazzali M, Kanbay M, Segal MS, Shafiu M, Jalal D, Feig DI, Johnson RJ. Uric acid and hypertension: cause or effect? CurrRheumatol Rep. 2010 Apr;12(2):10817.

10. Alper AB Jr, Chen W, Yau L, Srinivasan SR, Berenson GS, Hamm LL. Childhood uric acid predicts adult blood pressure: the Bogalusa Heart Study. Hypertension. 2005 Jan;45(1):34-8.

11. Jossa F, Farinaro E, Panico S, Krogh V, Celentano E, Galasso R, Mancini M, Trevisan M. Serum uric acid and hypertension: the Olivetti heart study.J Hum Hypertens. 1994 Sep;8(9):677-81.

12. Iliesiu A, Campeanu A, Dusceac D. Serum uric acid and cardiovascular disease. Maedica (Bucur). 2010;5(3):186-192. 